\title{
Context-Dependent Recognition Is Related to Specific Processes Taking Place at Encoding and at Retrieval
}

\author{
Tamar Silberg1,2, Eli Vakil ${ }^{3}$ \\ ${ }^{1}$ Department of Psychology, Bar-Ilan University, Ramat-Gan, Israel \\ ${ }^{2}$ The Edmond and Lily Safra Children's Hospital, Tel-Hashomer, Ramat-Gan, Israel \\ ${ }^{3}$ Department of Psychology and Leslie and Susan Gonda (Goldschmied) Multidisciplinary Brain Research Center, Bar-Ilan \\ University, Ramat-Gan, Israel \\ Email: tamarsilberg@gmail.com
}

How to cite this paper: Silberg, T., \& Vakil, E. (2017). Context-Dependent Recognition Is Related to Specific Processes Taking Place at Encoding and at Retrieval. Psychology, 8, 335-349. https://doi.org/10.4236/psych.2017.83020

Received: December 17, 2016

Accepted: February 11, 2017

Published: February 14, 2017

Copyright $\odot 2017$ by authors and Scientific Research Publishing Inc. This work is licensed under the Creative Commons Attribution International License (CC BY 4.0).

http://creativecommons.org/licenses/by/4.0/

(c) (i) Open Access

\begin{abstract}
Context Effect (CE) refers to the facilitation of memory for target information due to the similarity of contextual information available during both learning and retrieval. Many studies have attempted to identify variables that influence this effect, producing inconsistent findings due to differences in how target and context information are defined and measured. In the current study, recognition memory for faces was tested under different learning instructions and diverse context-recognition conditions. When memory instructions were used, recognition rates proved higher for the original target-context pairs than for all other possible target-context conditions. A different CE profile was observed for attentional instructions while old, yet not necessarily original, target-context faces yielded better results than other context conditions. These findings indicate that memory instructions lead to $\mathrm{CE}$ based on the formation of a specific association between target and context information, while instructions focusing on attentional resources lead to CE based on familiarity judgments. The double dissociation reported here is that memory instructions yield binding as opposed to familiarity type of $\mathrm{CE}$, while attention instructions yield familiarity and not binding type of $\mathrm{CE}$, supporting the claim that $\mathrm{CE}$ is not homogeneous and involves a number of cognitive processes.
\end{abstract}

\section{Keywords}

Context-Effect, Learning, Memory, Attention

\section{Introduction}

As a rule, humans perceive and are affected by not only the discrete objects and 
events at the focus of their attention, but also a wide range of factors that form the context of that information. Such contextual elements affect the interpretation of the stimuli of interest, put them in a particular perspective, and often influence the probability that they will be remembered later on (Foos \& Goolkasian, 2008). The phenomenon described above is well known in cognitive literature as the context effect (CE) (Dennis \& Humphreys, 2001; Murnane \& Phelps, 1993, 1994; Russo, Ward, Geurts, \& Scheres, 1999).

Findings regarding $\mathrm{CE}$ in recognition memory are inconsistent. Some studies suggest that context facilitates target memory (Hollingworth, 2006; Parker \& Gellatly, 1997), whereas others fail to demonstrate this effect (Murnane \& Phelps, 1993, 1994). Several interpretations are offered to explain the inconsistencies. For example, Murnane and Phelps (1994) suggested that CE would emerge only when totally new contexts are contrasted with old contexts for both targets and foils and Russo et al. (1999) posited that CE emerge in recognition only for novel stimuli, since for very familiar items existing representations may be employed to construct a strong episodic trace at encoding, obviating the need for contextual information. In addition, Vakil, Raz, and Levy (2007) emphasized the importance of the different context-retrieval conditions to the emergence and magnitude of $\mathrm{CE}$ on recognition. In this study we address two major factors that might be related to these inconsistencies: how target and context information are defined, and how they are measured at retrieval.

\subsection{Definitions of Target and Context Information}

The way that "target" and "context" stimuli are operationally defined in various laboratory studies ${ }^{1}$ could be one of the factors affecting the abovementioned inconsistencies. The CE literature showed that at encoding, specific learning instructions can help distinguish target from context information (Hirst \& Volpe, 1984; Steyvers \& Malmberg, 2003). Two different types of instructions can be identified as reflecting different elaborative approaches during encoding: (I) remembering the target (hereafter, the memory approach), and (II) directing attention to the target without an explicit instruction to remember (hereafter, the attention approach). According to the memory approach, the instruction to remember is the critical component that defines particular information as a target. Information that accompanies the target stimulus at the learning phase but that is not expected to be remembered is defined as context (Baddeley, 1982; Baddeley \& Woodhead, 1982; Davies \& Milne, 1982; Priestley \& Mayes, 1992; Watkins, Ho, \& Tulving, 1976). Other studies followed the attention approach and focused on attention rather than on memory processes in order to differentiate target from context. For example, Mayes, MacDonald, Donlan, Pears, and Meudell (1992) defined context as "information that falls on the periphery of attention" (p. 268). Although the two approaches emphasize different elaboration processes for the target and context information, they seem to share a common

${ }^{1}$ Studies focusing on more general, environmental contexts are beyond the scope of this study and thus not described in detail in the theoretical background. For a review, see Smith and Vela (2001). 
feature. In both, target and context information differ in the cognitive resources allocated to them; that is, relatively more cognitive resources are allocated to the target information than to the context information (Dennis \& Humphreys, 2001; Jacoby, 1991; Steyvers \& Malmberg, 2003).

However, target and context information can be determined not only at the encoding phase, as described above, but also at the retrieval phase. In some studies, better recognition of either member of an equally and jointly processed pair of stimuli (i.e., Pair Associate Learning: PAL) is viewed as a legitimate case of CE (Bower \& Karlin, 1974; Clark \& Gronlund, 1996; Feenan \& Snodgrass, 1990; Humphreys \& Bain, 1983; Reingold \& Goshen-Gottstein, 1996; Watkins et al., 1976). Thus, when target and context are defined at retrieval, the way target information is measured is usually by directly presenting one stimulus as a cue for the recall of the other (e.g., Meltzer \& Constable, 2005; Vakil \& Oded, 2003) or by executing a recognition test in which original and recombined pairs are to be discriminated (e.g., Giovanello, Keane, \& Verfaellie, 2006; Giovanello, Verfaellie, \& Keane, 2003; Stark \& Squire, 2003). Although these conditions of equal processing at encoding are not considered canonical target-context relationships, they are certainly of interest. In such PAL paradigms, the way the target stimulus is highlighted during retrieval has an impact on the target-context relationship and, as a result, influences the emergence of CE.

\subsection{Different Context-Retrieval Conditions}

Recent studies have also demonstrated that CE is not a homogeneous phenomenon. Instead, it reflects several memory-related cognitive processes that are often revealed when contextual changes between encoding and retrieval occur (Gruppuso, Lindsay, \& Masson, 2007; Hockley, 2008; Winograd \& Rivers-Bulkeley, 1977). Differences in context-retrieval conditions are thus another important factor potentially related to the inconsistent reports in CE studies regarding the contribution of context information to recognition. Vakil et al. (2007) proposed a multifactorial model of $\mathrm{CE}$ that distinguishes between different components of the CE itself by comparing four different context-retrieval conditions: (I) Repeat: when target information is presented together with its original context, (II) Re-pair: when target information is presented with context previously presented yet paired with a different target item, (III) New: when target information is presented with context never previously presented, and (IV) None: when target stimulus is presented alone. The different context retrieval conditions allow measuring the unique dependence of target memory on contextual information, based on multiple processes. For example, findings of better target memory in Repeat vs. New or None conditions are open to different interpretations. It is possible that the old context merely increased the familiarity of the pair (two old items) compared to the alternatives (one old item). The claim that an association was formed between the specific target and the specific context cannot be conclusively made in such a case (Baddeley \& Woodhead, 1982; Bower \& Karlin, 1974; Macken, 2002). Furthermore, the New and None condi- 
tions may have qualitatively different effects on target memory. For example, Winograd and Rivers-Bulkeley (1977) found a benefit of interactive T-C encoding of faces (which they call unitization) for the Repeat condition only relative to the New condition, but not relative to the None condition. Similarly, Tulving and Thomson (1971) found that for strongly associated word pairs, the None condition yielded poorer memory than the New condition, while for weakly associated word pairs, the opposite result obtained.

In the present study, we used pairs of faces as the stimuli. Many CE studies use target and context stimuli that are perceptually equivalent (e.g., pairs of faces or words; Murnane \& Phelps, 1994; Reder et al., 2002; Smith, 1979). These studies are of special interest because there is no a-priori reason to allocate more cognitive resources to one stimulus than to the other, unless a specific instruction was given. The advantage of such paradigms is that the designation of a stimulus as a target or context is controlled. Moreover, using pairs of faces, which are rich in information, increases resemblance in elaboration efforts and reduces variability in encoding strategies between participants (Foos \& Goolkasian, 2008; Taconnat, Froger, Sacher, \& Isingrini, 2008).

According to the above, in the present study we examined two major factors possibly related to the inconsistencies described in the CE literature: the way the target and context information are defined, and the way they are measured at retrieval. We compared how context-dependent target recognition was affected by the different learning instructions (memory vs. attention) for target and context stimulus and by the stage of definition (encoding vs. retrieval [PAL]). During the test phase, we compared the advantage of $\mathrm{CE}$ for recognition of exact target-context pairs (Repeat condition) with its advantage while recalling targets that were recombined with contexts that were seen previously but paired with different targets (Re-pair condition). In addition, based on Vakil et al. (2007), we included two different context-negative conditions: the New condition, in which targets were accompanied by new faces that had not been seen during the study phase and in which we preserved the stimulus-array structure by presenting another face-pair structure, and the None condition, in which a single target face was presented without a context face.

We hypothesized that the different context-retrieval conditions would contribute differently to memory for targets, in accordance with the multifactorial model of CE described by Vakil et al. (2007). Furthermore, we expected an interaction between Learning-instructions and Context-retrieval conditions to emerge. Specifically, we expected that when memory instructions were given, hit rates would be higher when presenting the same pair (Repeat condition) at retrieval than for all other retrieval conditions (according to the ICE theory; Murnane, Phelps, \& Malmberg, 1999), and that when attentional learning instructions were given, a more global familiarity-based effect of context on memory would occur in both the Repeat and Re-pair conditions (Murnane \& Phelps, 1994). By taking this approach, we aimed to shift our study's paradigm further from the conventional dichotomous approach to $\mathrm{CE}$ as an "either/or" condition, 
and this may serve as a purer measure of memory processes.

\section{Methods}

\subsection{Participants}

Sixty undergraduate students at Bar-Ilan University, Central Israel (34 females; mean age 23, range 19 -34), self-reportedly in good health, took part in the experiment to fulfill their academic requirements. Written informed consent was obtained from all participants for a protocol approved by the Bar-Ilan University Institutional Review Board.

\subsection{Stimuli}

Ninety-six head-and-shoulder color portrait photographs (48 females and 48 males) were taken from the AR Face database (Martinez \& Benavente, 1998; see Figure 1 for an example of study stimuli). All images present a frontal view with neutral facial expressions and controlled background and illumination conditions. The stimuli were randomly arranged in same-gender pairs to form 24 study pairs (12 female pairs, 12 male pairs) and an additional 24 pairs for the various retrieval-pair combinations. Same-gender pairs were used to rule out gender bias in face recognition, which could arise due to subjective preference of participants to either the male or female picture within the pair (Lovén, Herlitz, \& Rehnman, 2011; Wright \& Sladden, 2003). The order of presentation of stimuli in both the learning and retrieval phases was randomized between participants.

The experimental design was a $2 \times 2 \times 4$ mixed analysis of variance (ANOVA) with type of Learning-instruction (memory vs. attention) and target Definition-phase (encoding vs. retrieval) as the between-subjects factors, and the Context-retrieval conditions (Repeat, Re-pair, New, and None) as the within-subject factor. Participants were randomly assigned to one of the four learning conditions

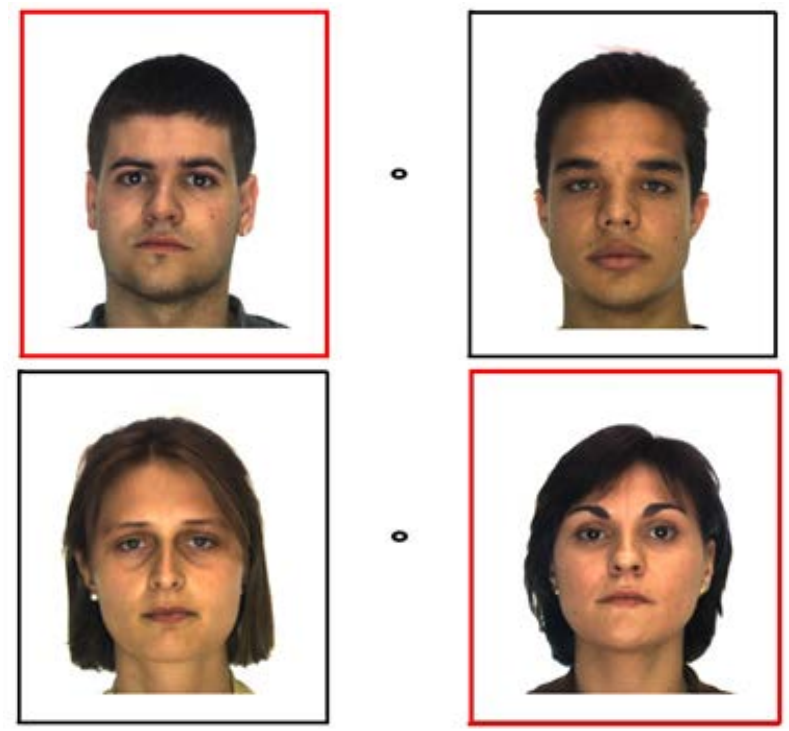

Figure 1. Example of study stimuli. 
with respect to extraneous factors such as age and gender. No significant differences were found for age and gender between the experimental groups $(F(3,59)=$ $0.63, p=0.6 ; X^{2}(3,60)=1.36, p=0.72$, respectively). All participants were told that they would see pairs of faces. Each group was given a different combination of learning instructions for the target and context stimuli (see Table 1 for description of the different learning instructions according to the four experimental groups).

\subsection{Procedure}

During the learning phase, 24 face-pairs were presented on a computer screen for 4 seconds each, using SuperLab (Cedrus, Inc.) software. Between the pairs, a filler image containing a fixation point was presented for 1 second to reduce sequential effects related to the position of the target face in the previous pair. Each slide contained two faces, $8.5 \times 10 \mathrm{~cm}$ each, $4 \mathrm{~cm}$ apart with a fixation point exactly in the middle. The faces were presented side by side, each with a rectangular border. The target faces were bordered with a red rectangle, and the context faces were bordered with a black rectangle. Target faces were counterbalanced between the left and right sides of the computer screen. The position of the red and black borders was held constant between encoding and retrieval; that is, if a target face (red border) was presented at the right side of the screen during encoding, it was presented in the identical position at retrieval. This exact repetition was done for all different retrieval conditions.

The identities of all faces were balanced across the different conditions, verifying the equal likelihood of the faces used as new, Repeat Re-pair, and No context. Thus, all stimuli were similar between participant groups. Each participant

Table 1. Description of the different learning instruction conditions, by experimental group.

\begin{tabular}{|c|c|c|c|c|}
\hline Group & $\begin{array}{l}\text { Instruction directed } \\
\text { to target face }\end{array}$ & $\begin{array}{l}\text { Instruction directed to } \\
\text { context face }\end{array}$ & $\begin{array}{l}\text { Approach } \\
\text { equivalent }\end{array}$ & $\begin{array}{l}\text { Phase of } \\
\text { definition }\end{array}$ \\
\hline 1 & $\begin{array}{l}\text { Look at the face in the red } \\
\text { rectangle and try to } \\
\text { remember it for a } \\
\text { memory test }\end{array}$ & No instruction & Memory & Encoding* \\
\hline 2 & $\begin{array}{l}\text { Look at the face in the red } \\
\text { rectangle and try to } \\
\text { remember it for a } \\
\text { memory test }\end{array}$ & $\begin{array}{l}\text { Look at the face in the } \\
\text { black rectangle and try to } \\
\text { remember it for a } \\
\text { memory test }\end{array}$ & Memory & Retrieval $^{* *}$ \\
\hline 3 & $\begin{array}{l}\text { Look at the face in the red } \\
\text { rectangle and try to decide } \\
\text { whether you like it or not }\end{array}$ & No instruction & Attention & Encoding \\
\hline 4 & $\begin{array}{l}\text { Look at the face in the red } \\
\text { rectangle and decide } \\
\text { whether you like it or not }\end{array}$ & $\begin{array}{l}\text { Look at the face in the } \\
\text { black rectangle and decide } \\
\text { whether you like it or not }\end{array}$ & Attention & Retrieval \\
\hline
\end{tabular}

Note. ${ }^{*}$ Differential learning instructions at encoding; ${ }^{* *}$ Identical learning instructions at encoding (PAL), differentiation at retrieval. 
performed four practice trials before beginning the experiment. The trials were not included in the results analysis. After the study phase, participants in all learning conditions were asked to wait for 1 hour in a separate, quiet room for the second part of the experiment, in which they performed an identical recognition test. While they were waiting, the researcher asked them to provide demographic information.

During the retrieval phase, participants were asked to indicate whether the face with the red border had been presented during the study phase or not. Specifically, participants were told to answer "yes" if the face presented to them at retrieval was the face that appeared with a red border during the study phase. Responses were recorded using the SuperLab (Cedrus, Inc.) program. Two stickers indicating "Yes" and "No" were pasted on the " $A$ " and "L" keys on the keyboard. None of the faces that appeared in black borders during encoding were used as target faces during retrieval.

Seven types of retrieval pairs, each forming a different retrieval-context condition, were presented to all participants in random order. Four types of pairs displayed an original target face with different combinations of context faces, and three types of pairs displayed new target faces with the same combinations of context faces (see Table 2 for a detailed description of retrieval-context conditions).

Statistical analyses were performed using SPSS version 19.0 for Windows (SPSS-19). G*Power 3 software, was used to calculate the sample size required for achieving power greater than 0.95 .

\subsection{Data Analysis}

A repeated-measure ANOVA was conducted with Type of Learning-instruction (memory vs. attention) and Definition-phase (encoding vs. retrieval) as the between-subjects factors and the Context-retrieval conditions (Repeat, Re-pair, New, and None) as the within-subject factor.

Table 2. Detailed description of all retrieval-context conditions.

\begin{tabular}{|c|c|c|}
\hline \multirow{2}{*}{ Study pairs } & \multicolumn{2}{|c|}{ Retrieval pairs } \\
\hline & Old target faces & New target faces \\
\hline \multirow{11}{*}{$\begin{array}{c}24 \text { same-gender } \\
\text { pairs }\end{array}$} & Repeat $=6$ identical, previously & \multirow{6}{*}{$\begin{array}{l}12 \text { new unstudied faces presented } \\
\text { in the context of a face that had } \\
\text { been viewed during the study } \\
\text { phase with a different face. }\end{array}$} \\
\hline & studied target and context pairs. & \\
\hline & $R e-$ pair $=6$ pairs of studied target & \\
\hline & faces presented with context faces & \\
\hline & seen during the study phase & \\
\hline & with different target faces. & \\
\hline & $N e w=6$ pairs of studied target faces & \multirow{3}{*}{6 pairs of new, unstudied faces. } \\
\hline & $\begin{array}{l}\text { presented with new context faces } \\
\text { that had not been seen }\end{array}$ & \\
\hline & during the study phase. & \\
\hline & None $=6$ studied target faces & 6 new, unstudied faces \\
\hline & unaccompanied by any other face. & unaccompanied by any other face. \\
\hline
\end{tabular}


According to the two-high threshold model (Snodgrass \& Corwin, 1988), the measure of discrimination rate, commonly known as the corrected-hits score, was used as the dependent variable as it represents the difference between hits and FA rates $(\mathrm{Pr}=$ Hits $-\mathrm{FA})$. The upper-bound value for $\operatorname{Pr}$ is 1 .

\section{Results}

\section{Discrimination-Rate (Corrected Hits) Analysis}

A significant main effect for Context-retrieval conditions was found, $F(3,168)=$ $8.42, p<0.001, \eta^{2}=0.13$. However, this finding should be interpreted with caution due to the significant interaction found between the Type of Learning-instruction and the Context-retrieval Conditions, $F(3,168)=4.43, p<0.005$, $\eta^{2}=0.07$

To examine the source of this interaction, we conducted separate analyses for each Learning-instruction group. These analyses revealed a different profile for each Context-retrieval condition (see Figure 2):

1) In the Memory-learning instruction group, we found a significant difference between the Repeat and all other retrieval conditions (Re-pair, $F(1,29)=$ 7.81, $p<0.001$; New, $F(1,29)=3.92, p<0.001$; None, $F(1,29)=3.97, p<0.01)$. No significant differences were found between all other Context-retrieval conditions $(p>0.05)$.

2) In the Attention-learning instruction group, we found significant differences between the Repeat and New conditions $(F(1,29)=2.86, p<0.01)$ and between the Re-pair and New and None conditions $(F(1,29)=3.27, p<0.01$; $F(1,29)=2.02, p<0.05)$. No significant differences were found between the other Context-retrieval conditions $(p>0.05)$.

Significant main effects for the type of Learning-instruction and the Definition-phase conditions were also found. Higher discrimination rates were found

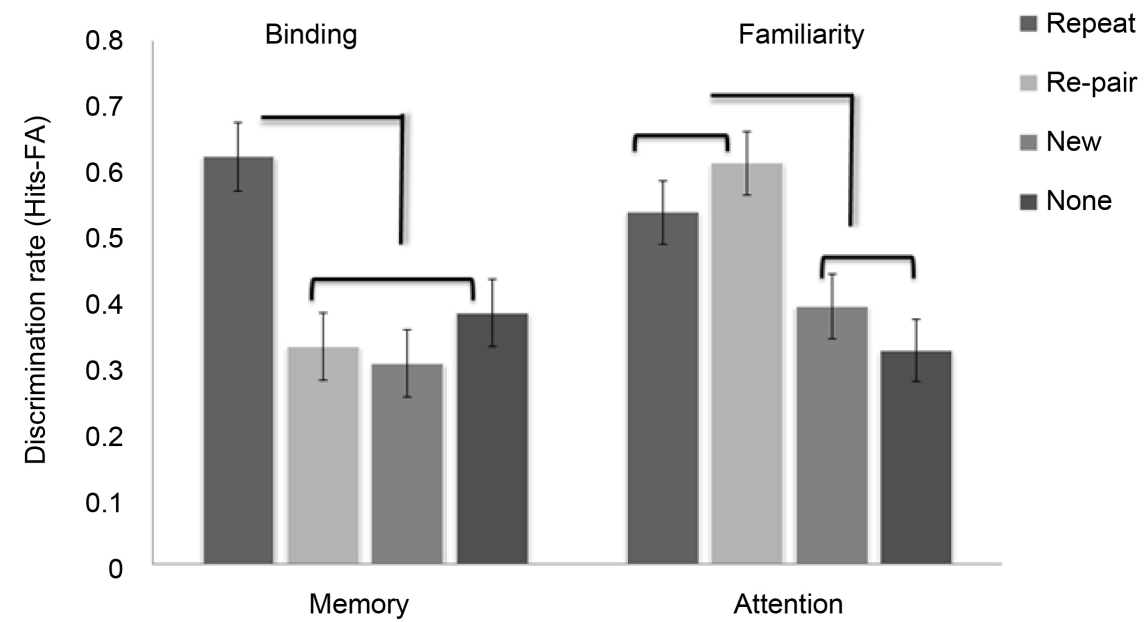

Figure 2. Percentage of discrimination rate $(\mathrm{Pr})$ in the four Context-retrieval conditions: Repeat, Re-pair, New, and None. Memory = Memory learning instructions; Attention = Attentional learning instructions. Brackets atop columns indicate standard deviation of the mean. 
in the Memory-learning instruction condition $(M=0.49 ; S D=0.3)$, compared with the Attention-learning instruction condition $(M=0.38 ; S D=0.3)(F(1,56)=$ 5.58, $\left.p<0.05, \eta^{2}=0.09\right)$. Subsequently, higher discrimination rates were found for the Encoding-phase $(M=0.49 ; S D=0.31)$ compared with the Retrieval-phase condition $(M=0.38 ; S D=0.31), F(1,56)=6.2, p<0.05, \eta^{2}=0.12$.

We found no significant interaction between type of Learning-instruction and Definition-phase, $F(1,56)=0.75, p>0.05, \eta^{2}=0.02$, or between the Learning-instruction, Definition-phase, and Context-retrieval conditions, $F(3,168)=$ $1.83, p>0.05, \eta^{2}=0.001$.

\section{Discussion}

This study was motivated by the underlying assumption that target and context are dissociated on the basis of different encoding and retrieval processes. We examined whether different definitions of target and context information and the phase in which these definitions are made would affect the emergence of CE during recognition tests. Pairs of faces were used as study stimuli. All participants were tested under various contextual conditions. Our most significant finding was that different definitions of target and context information yielded different patterns of CE as measured using different context-retrieval conditions. This supports our hypothesis regarding the contribution of these two factors (i.e., target-context definition and various measures of $\mathrm{CE}$ ) to the inconsistent reports in the CE literature.

We manipulated different kinds of learning instructions for target and context information as well as the definition phase in which target faces were distinguished from context faces (Table 1). Analyses were conducted using the sensitive measure of discrimination rate $(\mathrm{Pr})$.

Under memory instruction conditions, participants were instructed to memorize a target face. The results indicated that instructions to remember the target face yielded an advantage for recognition of exact targe-context pairs (i.e., Repeat > Re-pair, New, and None). This advantage reflects the core aspect of CE, which is dependent on specific binding at the study phase between target and context information (Foos \& Goolkasian, 2008; Hollingworth, 2006). The advantage for the Repeat condition was found regardless of the definition phase (i.e., encoding or retrieval) and the specific response measure used (i.e., hits or discrimination rate). Target and context binding was obtained only under an explicit instruction to memorize the target face, suggesting that the cue set for specific binding is initiated with the simple activation of a memory instruction at encoding, regardless of any request referring to the context information. Our findings are consistent with Macken's (2002) view that CEs arise due to specific associations between target items and their study contexts. This finding also converges with the work of Hunt (2003), who argued that distinctiveness can play a role in enhancing recollection of studied items as well as in rejecting familiar, unstudied items. In our results, specific binding under the influence of the memory instruction may have helped participants reject unstudied pairs by 
using a recollect-to-reject strategy (Rotello \& Heit, 2000).

The specific target-context binding effect was not found under the attention-learning instruction condition, thus supporting the abovementioned memory-induced binding hypothesis. When attention-learning instructions were given, a familiarity-based CE pattern (i.e., Repeat $=$ Re-pair $>$ New, None) was found. These results are not in line with the conclusions presented by Hayes, Nadel, and Ryan (2007) in which binding of object and context stimuli occurred under both intentional and incidental conditions (corresponding respectively to the memory and attention conditions in the current study). They suggested that binding of an object and context is relatively automatic, impervious to the intentions of the participant. A possible explanation for the incompatibility between the two studies is that the stimuli used by Hayes et al. consisted of objects and scenes that may be integrated and encoded as a single visual scene, enhancing binding between the two. The faces used in the current study apparently did not cause such automatic binding.

We found that the overall recognition score was higher under the encoding-phase condition compared with the retrieval-phase condition. The current results highlight the different underlying processes that take place during encoding compared with those apparent at retrieval. More specifically, it can be assumed that the contribution of context information to later recognition memory depends on the effortful processing allocated to target as opposed to context at encoding (Hirst \& Volpe, 1984). The relationship between the two paradigms is quite informative, although to our knowledge no direct comparison between the two types of learning paradigms has been made to reveal these unique underlying processes. This argument extends beyond theoretical concern. Comparisons of this kind could help develop a better understanding of the unique contribution of each type of learning to later memory performance in our demanding environment.

The comparison between the different learning instructions under the various retrieval conditions, using discrimination rate analysis, enabled us to evaluate when $\mathrm{CE}$ emerges under the suggested theoretical approaches (memory vs. attention) and in what way. Our results support the difference between the two approaches. Although CE did emerge when both approaches were tested, the different CE profiles found highlight the possibility of different retrieval properties related to specific encoding conditions. Had we compared only part of the possible context-retrieval conditions as reported in previous studies (Hayes et al., 2007), it is certainly possible that not all of the different CEs would have been revealed.

Another important implication of the results shown here is the general dissociation between the effect of memory- and attention-learning instructions on recognition. Using the sensitive measure of discrimination rate, we could address the classic question in memory research regarding the difference between processing of information with the intention to remember it (i.e., intentional learning) and the equivalent processing in the absence of a specific intention to 
remember (i.e., incidental learning) (Armstrong \& McKelvie, 1996; Foos \& Goolkasian, 2008). In their seminal research on this question, Craik and Lockhart (1972) argued that the level of processing (LoP) of stimulus material is the direct determinant of how well that material will be remembered, regardless of intent to remember it. The current results further support Koriat and Melkman (1987) that claim that the information that is committed to memory may be represented and organized in many alternative forms, and thus it is important to determine which factors affect the organization method.

The current study has several limitations. First, the results presented here are preliminary with a relatively small sample, and although the effects presented were robust as indicated by the moderate-to-high effect sizes, further analysis should be conducted using larger sample sizes. Second, using additional learning instruction conditions, such as the unitization or grouping of face stimuli under the different learning and definition conditions (Yonelinas et al., 1999) could help clarify the different elaboration mechanisms involved in recognition memory. Such conditions could help determine the extent of the effect various learning instructions have on the unique CE profile (Ahmad \& Hockley, 2014). Third, we used typical, sensitive measures of memory performance that have been reported in previous studies as representing different recognition strategies (Fernandes \& Guild, 2009; Gillund \& Shiffrin, 1984). Yet, in order to illustrate a more sensitive accuracy measure in accordance with modern signal-detection theories, participants should have indicated their level of confidence when recognizing stimuli as old or not (Busey, Tunnicliff, Loftus, \& Loftus, 2000; Tunney, Mullett, Moross, \& Gardner, 2012). Finally, although our study manipulated the learning instructions, we could not guarantee that participants followed the instructions they received when encoding both target and context faces. Further studies using more sensitive measures (i.e., eye-tracking devices) might shed light on how participants encode visual information for different experimental manipulations such as the one reported here.

Although preliminary, the current results serve as a point of departure for $\mathrm{CE}$ literature and are of significant theoretical importance, as they further support the claim that the $\mathrm{CE}$ is not homogeneous but rather involves a number of cognitive processes. The double dissociation reported here-that memory instructions yielded a binding as opposed to a familiarity type of $\mathrm{CE}$ whereas attention instructions yielded a familiarity as opposed to a binding type of CE-support the multifactorial model of CE proposed by Vakil et al. (2007). The results presented here demonstrate the independence of the binding and familiarity types of CE proposed by this model.

\section{References}

Ahmad, F. N., \& Hockley, W. E. (2014). The Role of Familiarity in the Associative Recognition of Unitized Compound Word Pairs. Quarterly Journal of Experimental Psychology, 67, 2301-2324. https://doi.org/10.1080/17470218.2014.923007

Armstrong, H. A., \& McKelvie, S. J. (1996). Effect of Face Context on Recognition Mem- 
ory for Voices. The Journal of General Psychology, 123, 259-270.

https://doi.org/10.1080/00221309.1996.9921278

Baddeley, A. D. (1982). Domains of Recollection. Psychological Review, 89, 708-729. https://doi.org/10.1037/0033-295X.89.6.708

Baddeley, A. D., \& Woodhead, M. (1982). Depth of Processing, Context, and Face Recognition. Canadian Journal of Psychology, 36, 148-164.

https://doi.org/10.1037/h0080635

Bower, G. H., \& Karlin, M. B. (1974). Depth of Processing Pictures of Faces and Recognition Memory. Journal of Experimental Psychology, 103, 751-757. https://doi.org/10.1037/h0037190

Busey, T. A., Tunnicliff, J., Loftus, G. R., \& Loftus, E. F. (2000). Accounts of the Confidence-Accuracy Relation in Recognition Memory. Psychonomic Bulletin \& Review, 7, 26-48. https://doi.org/10.3758/BF03210724

Clark, S. E., \& Gronlund, S. D. (1996). Global Matching Models of Recognition Memory: How the Models Match the Data. Psychonomic Bulletin \& Review, 3, 37-60. https://doi.org/10.3758/BF03210740

Craik, F. I. M., \& Lockhart, R. S. (1972). Levels of Processing: A Framework for Memory Research. Journal of Verbal Learning and Verbal Behavior, 11, 671-684. https://doi.org/10.1016/S0022-5371(72)80001-X

Davies, G., \& Milne, A. (1982). Recognizing Faces In and Out of Context. Current Psychological Research, 2, 235-246. https://doi.org/10.1007/BF03186766

Dennis, S., \& Humphreys, M. S. (2001). A Context Noise Model of Episodic Word Recognition. Psychological Review, 108, 452-478. https://doi.org/10.1037/0033-295X.108.2.452

Feenan, K., \& Snodgrass, J. G. (1990). The Effect of Context on Discrimination and Bias in Recognition Memory for Pictures and Words. Memory \& Cognition, 18, 515-527. https://doi.org/10.3758/BF03198484

Fernandes, M., \& Guild, E. (2009). Process-Specific Interference Effects during Recognition of Spatial Patterns and Words. Canadian Journal of Experimental Psychology, 6, 24-32. https://doi.org/10.1037/a0012870

Foos, P. W., \& Goolkasian, P. (2008). Presentation Format Effects in a Levels-ofProcessing Task. Experimental Psychology, 55, 215-227.

https://doi.org/10.1027/1618-3169.55.4.215

Gillund, G., \& Shiffrin, R. M. (1984). A Retrieval Model for Both Recognition and Recall. Psychological Review, 91, 1-67. https://doi.org/10.1037/0033-295X.91.1.1

Giovanello, K. S., Keane, M. M., \& Verfaellie, M. (2006). The Contribution of Familiarity to Associative Memory in Amnesia. Neuropsychologia, 44, 1859-1865. https://doi.org/10.1016/j.neuropsychologia.2006.03.004

Giovanello, K. S., Verfaellie, M., \& Keane, M. M. (2003). Disproportionate Impairment in Associative Recognition Relative to Item Recognition in Global Amnesia. Cognitive, Affective \& Behavioral Neuroscience, 3, 186-194. https://doi.org/10.3758/CABN.3.3.186

Gruppuso, V., Lindsay, D. S., \& Masson, M. E. J. (2007). I'd Know That Face Anywhere! Psychonomic Bulletin \& Review, 14, 1085-1089. https://doi.org/10.3758/BF03193095

Hayes, S. M., Nadel, L., \& Ryan, L. (2007). The Effect of Scene Context on Episodic Object Recognition: Parahippocampal Cortex Mediates Memory Encoding and Retrieval Success. Hippocampus, 17, 873-889. https://doi.org/10.1002/hipo.20319

Hirst, W., \& Volpe, B. T. (1984). Encoding of Spatial Relations with Amnesia. Neuropsy- 
chologia, 22, 631-634. https://doi.org/10.1016/0028-3932(84)90029-0

Hockley, W. E. (2008). The Effects of Environmental Context on Recognition Memory and Claims of Remembering. Journal of Experimental Psychology: Learning, Memory \& Cognition, 34, 1412-1429. https://doi.org/10.1037/a0013016

Hollingworth, A. (2006). Scene and Position Specificity in Visual Memory for Objects. Journal of Experimental Psychology: Learning, Memory, and Cognition, 32, 58-69. https://doi.org/10.1037/0278-7393.32.1.58

Humphreys, M. S., \& Bain, J. D. (1983). Recognition Memory: A Cue and Information Analysis. Memory and Cognition, 11, 583-600. https://doi.org/10.3758/BF03198283

Hunt, R. R. (2003). Two Contributions of Distinctive Processing to Accurate Memory. Journal of Memory and Language, 48, 811-825. https://doi.org/10.1016/S0749-596X(03)00018-4

Jacoby, L. L. (1991). A Process Dissociation Framework: Separating Automatic from Intentional Uses of Memory. Journal of Memory and Language, 30, 513-541. https://doi.org/10.1016/0749-596X(91)90025-F

Koriat, A., \& Melkman, R. (1987). Depth of Processing and Memory Organization. Psychological Research, 49, 173-181. https://doi.org/10.1007/BF00308684

Lovén, J., Herlitz, A., \& Rehnman, J. (2011). Women’s Own-Gender Bias in Face Recognition Memory. Experimental Psychology, 58, 333-340.

https://doi.org/10.1027/1618-3169/a000100

Macken, W. J. (2002). Environmental Context and Recognition: The Role of Recollection and Familiarity. Journal of Experimental Psychology: Learning, Memory, and Cognition, 28, 153-161. https://doi.org/10.1037/0278-7393.28.1.153

Martinez, A. M., \& Benavente, R. (1998). The AR Face Database. CVC Technical Report No. 24.

Mayes, A. R., MacDonald, C., Donlan, L., Pears, J., \& Meudell, P. R. (1992). Amnesics Have a Disproportionately Severe Memory Deficit for Interactive Context. Quarterly Journal of Experimental Psychology, 45, 265-297. https://doi.org/10.1080/14640749208401327

Meltzer, J. A., \& Constable, R. T. (2005). Activation of Human Hippocampal Formation Reflects Success in Both Encoding and Cued Recall of Paired Associates. NeuroImage, 24, 384-397. https://doi.org/10.1016/j.neuroimage.2004.09.001

Murnane, K., \& Phelps, M. P. (1993). A Global Activation Approach to the Effect of Changes in Environmental Context on Recognition. Journal of Experimental Psychology: Learning, Memory, and Cognition, 19, 882-894.

https://doi.org/10.1037/0278-7393.19.4.882

Murnane, K., \& Phelps, M. P. (1994). When Does a Different Environmental Context Make a Difference in Recognition? A Global Activation Model. Memory \& Cognition, 22, 584-590. https://doi.org/10.3758/BF03198397

Murnane, K., Phelps, M. P., \& Malmberg, K. (1999). Context-Dependent Recognition Memory: The ICE Theory. Journal of Experimental Psychology: General, 128, 403-415. https://doi.org/10.1037/0096-3445.128.4.403

Parker, A., \& Gellatly, A. (1997). Movable Cues: A Practical Method for Reducing Context-Dependent Forgetting. Applied Cognitive Psychology, 11, 163-173. https://doi.org/10.1002/(SICI)1099-0720(199704)11:2<163::AID-ACP427>3.0.CO;2-1

Priestley, N. M., \& Mayes, A. R. (1992). Preservation of Priming for Interactive Context in Amnesics. Cortex, 28, 555-574. https://doi.org/10.1016/S0010-9452(13)80227-4

Reder, L. M., Donavos, D. K., \& Erickson, M. A. (2002). Perceptual Match Effects in Di- 
rect Tests of Memory: The Role of Contextual Fan. Memory \& Cognition, 30, 312-323. https://doi.org/10.3758/BF03195292

Reingold, E. M., \& Goshen-Gottstein, Y. (1996). Separating Consciously Controlled and Automatic Influences in Memory for New Associations. Journal of Experimental Psychology: Learning, Memory, and Cognition, 22, 397-406. https://doi.org/10.1037/0278-7393.22.2.397

Rotello, C. M., \& Heit, E. (2000). Two-Process Models of Recognition Memory: Evidence for Recall-to-Reject? Journal of Memory and Language, 40, 432-453. https://doi.org/10.1006/jmla.1998.2623

Russo, R., Ward, G., Geurts, H., \& Scheres, A. (1999). When Unfamiliarity Matters: Changing Environmental Context between Study and Test Affects Recognition Memory for Unfamiliar Stimuli. Journal of Experimental Psychology: Learning, Memory, and Cognition, 25, 488-499. https://doi.org/10.1037/0278-7393.25.2.488

Smith, S. M. (1979). Remembering in and out of Context. Journal of Experimental Psychology: Human Learning and Memory, 5, 460-471. https://doi.org/10.1037/0278-7393.5.5.460

Smith, S. M., \& Vela, E. (2001). Environmental Context-Dependent Memory: A Review and Meta-Analysis. Psychonomic Bulletin \& Review, 8, 203-220.

https://doi.org/10.3758/BF03196157

Snodgrass, J. G., \& Corwin, J. (1988). Pragmatics of Measuring Recognition Memory: Applications to Dementia and Amnesia. Journal of Experimental Psychology: General, 117, 34-50. https://doi.org/10.1037/0096-3445.117.1.34

Stark, C. E., \& Squire, L. R. (2003). Hippocampal Damage Equally Impairs Memory for Single Items and Memory for Conjunctions. Hippocampus, 13, 281-292. https://doi.org/10.1002/hipo.10085

Steyvers, M., \& Malmberg, K. J. (2003). The Effect of Normative Context Variability on Recognition Memory. Journal of Experimental Psychology: Learning, Memory, and Cognition, 29, 760-766. https://doi.org/10.1037/0278-7393.29.5.760

Taconnat, L., Froger, C., Sacher, M., \& Isingrini, M. (2008). Generation and Associative Encoding in Young and Old Adults: The Effect of the Strength of Association between Cues and Targets on a Cued Recall Task. Experimental Psychology, 55, 23-30. https://doi.org/10.1027/1618-3169.55.1.23

Tulving, E., \& Thomson, D. M. (1971). Retrieval Processes in Recognition Memory: Effects of Associative Context. Journal of Experimental Psychology, 87, 116-124. https://doi.org/10.1037/h0030186

Tunney, R. J., Mullett, T. L., Moross, C. J., \& Gardner, A. (2012). Does the Butcher-on-the-Bus Phenomenon Require a Dual-Process Explanation? A Signal Detection Analysis. Frontiers in Psychology, 3, 208. https://doi.org/10.3389/fpsyg.2012.00208

Vakil, E., \& Oded, Y. (2003). Comparison between Three Memory Tests: Cued Recall, Priming and Saving Closed-Head Injured Patients and Controls. Journal of Clinical and Experimental Neuropsychology, 25, 274-282. https://doi.org/10.1076/jcen.25.2.274.13637

Vakil, E., Raz, T., \& Levy, D. A. (2007). Multifactorial Context Effects on Visual Recognition Memory. Quarterly Journal of Experimental Psychology, 60, 916-923. https://doi.org/10.1080/17470210701357568

Watkins, M. J., Ho, E., \& Tulving, E. (1976). Context Effects in Recognition Memory for Faces. Journal of Verbal Learning \& Verbal Behavior, 15, 505-517. https://doi.org/10.1016/0022-5371(76)90045-1

Winograd, E., \& Rivers-Bulkeley, N. T. (1977). Effects of Changing Context on Remem- 
bering Faces. Journal of Experimental Psychology: Human, Learning and Memory, 3, 397-405. https://doi.org/10.1037/0278-7393.3.4.397

Wright, D. B., \& Sladden, B. (2003). An Own Gender Bias and the Importance of Hair in Face Recognition. Acta Psychologica, 114, 101-114.

https://doi.org/10.1016/S0001-6918(03)00052-0

Yonelinas, A. P., Kroll, N. E. A., Dobbins, I. G., \& Soltani, M. (1999). Recognition Memory for Faces: When Familiarity Supports Associative Recognition Judgments. Psychonomic Bulletin \& Review, 6, 654-661. https://doi.org/10.3758/BF03212975

Submit or recommend next manuscript to SCIRP and we will provide best service for you:

Accepting pre-submission inquiries through Email, Facebook, LinkedIn, Twitter, etc. A wide selection of journals (inclusive of 9 subjects, more than 200 journals)

Providing 24-hour high-quality service

User-friendly online submission system

Fair and swift peer-review system

Efficient typesetting and proofreading procedure

Display of the result of downloads and visits, as well as the number of cited articles Maximum dissemination of your research work

Submit your manuscript at: http://papersubmission.scirp.org/

Or contact psych@scirp.org 